\title{
Leptin as a predictor of metabolic syndrome in prepubertal children
}

Isabel Madeira', Maria Alice Bordallo², Nádia Cristina Rodrigues³, Cecilia Carvalho', Fernanda Gazolla ${ }^{5}$, Paulo Collett-Solberg ${ }^{2}$, Clarice Medeiros ${ }^{5}$, Ana Paula Bordallo ${ }^{5}$, Marcos Borges ${ }^{5}$, Claudia Monteiro ${ }^{5}$, Rebeca Ribeiro 6

\begin{abstract}
Objective: Leptin has been suggested as a potential biomarker of cardiovascular risk. This paper aims to ascertain, based on a sample of prepubertal children, which serum leptin value best suited to identify metabolic syndrome (MS). Subjects and methods: This observational, cross-sectional study recruited children from the outpatient pediatrics clinic, with the purpose of validating serum leptin level cutoffs to identify MS. All obese and overweight children who met eligibility criteria were included in the study, as was a sample of normal-weight children. The sample underwent clinical assessment and blood fasting glucose, lipid profile, insulin, and leptin were measured. Sensitivity and specificity were estimated for each leptin measurement, using MS as the outcome. These values were used to construct a receiver operating characteristic (ROC) curve. The association between MS and leptin was assessed using logistic models to predict MS. Results: A total of 65 normal weight, 46 overweight, and 164 obese children were analyzed (160 boys, 115 girls; age: $93.7 \pm 17.8$ months). The most appropriate leptin cutoff was $13.4 \mathrm{ng} / \mathrm{mL}$ (sensitivity 67.6\%; specificity $68.9 \%$; accuracy $72.1 \%$ ). The logistic model indicated that leptin levels above $13.4 \mathrm{ng} / \mathrm{dL}$ were significantly associated with MS and that, for every $1 \mathrm{ng} / \mathrm{dL}$ increase in leptin levels, the odds of MS increase by $3 \%(p=0.002$; OR 1.03; $95 \% \mathrm{Cl} 1.01-1.05)$. Conclusions: Leptin may be a useful biomarker of cardiovascular risk in prepubertal children, with an optimal cutoff of $13.4 \mathrm{ng} / \mathrm{mL}$. Identification of potential new risk markers for cardiovascular disease in children could contribute to the development of preventive strategies. Arch Endocrinol Metab. 2017;61(1):7-13
\end{abstract}

Keywords

Children; ROC curve; leptin; obesity; insulin resistance

\author{
1 Faculdade de Ciências Médicas, \\ Departamento de Pediatria, \\ Universidade do Estado do \\ Rio de Janeiro (UERJ), Rio \\ de Janeiro, RJ, Brasil \\ ${ }^{2}$ Faculdade de Ciências Médicas, \\ Departamento de Medicina Interna, \\ UERJ, Rio de Janeiro, RJ, Brasil \\ ${ }^{3}$ Faculdade de Ciências Médicas, \\ Departamento de Tecnologias da \\ Informação e Educação em Saúde, \\ UERJ, Rio de Janeiro, RJ, Brasil \\ ${ }^{4}$ Instituto de Nutrição, \\ Departamento de Nutrição Aplicada, \\ UERJ, Rio de Janeiro, RJ, Brasil \\ ${ }^{5}$ Hospital Universitário Pedro \\ Ernesto, Unidade Docente \\ Assistencial de Endocrinologia \\ e Metabologia, UERJ, Rio \\ de Janeiro, RJ, Brasil \\ ${ }^{6}$ Faculdade de Ciências Médicas, \\ UERJ, Rio de Janeiro, RJ, Brasil

\section{Correspondence to:} \\ Isabel Madeira \\ Av. 28 de Setembro, 77 \\ 20551-030 - Rio de Janeiro, RJ, Brasil \\ isamadeira@oi.com.br \\ Received on July/26/2015 \\ Accepted on Jan/4/2016 \\ DOI: 10.1590/2359-3997000000199
}

\section{INTRODUCTION}

$\mathrm{O}$ besity is currently a highly prevalent condition, including in Brazil $(1,2)$. The most significant complication of obesity, atherosclerotic cardiovascular disease, now constitutes the leading cause of death in adults in the western world. The main risk factors for cardiovascular disease are obesity, hypertension, dyslipidemia, and type 2 diabetes mellitus (T2DM), which together compose the so-called metabolic syndrome (MS). In this syndrome, insulin resistance and hyperinsulinemia would explain the core role of obesity and its association with the other abnormal phenomena observed. The effects of these factors appear to begin in childhood (3).

The pathophysiology of obesity involves an imbalance between energy intake and energy expenditure. Several neuroendocrine factors have been implicated in this energy imbalance, such as adipocytokines, proteins produced by adipose tissue. One of the most important adipocytokines is leptin.
This hormone signals, through central pathways, a decrease in food intake and increase in energy expenditure, in addition to having peripheral actions. In muscle, leptin stimulates fatty acid oxidation by activating adenosine monophosphate kinase. It also removes lipids from non-adipose tissue, preventing lipotoxicity, possibly due to its ability to block stearoylcoenzyme A desaturase, and inhibits hepatic triglyceride buildup by activating phosphatidylinositol 3-kinase (4).

Circulating leptin levels correlate with body adiposity in adults and children (5), and the high leptin levels found in obese individuals are believed to indicate leptin resistance (6). Furthermore, studies in children have shown that high leptin levels correlate with greater fat mass growth over time (7). Although most obese children have high leptin levels, mutations in the leptin receptors are rare. This adipokine is believed to cross the blood-brain barrier by means of a saturable transport system, which would limit its uptake by central receptors $(6)$. 
Other aspects related to leptin have been assessed in the pathophysiology of obesity. Leptin may contribute to insulin resistance and its metabolic correlates and appears to have a direct pro-thrombotic effect, in addition to acting synergistically with insulin and free fatty acids to stimulate sympathetic activity and vasoconstriction (8). Hence, leptin and insulin interact to modulate vascular function, and this interaction may have major implications in the vascular dysfunction of MS.

In the pediatric age range, obesity appears to be an important trigger of insulin resistance (3), which makes obese children a high-risk group and has led investigators to search for clinical and laboratory indicators in this population. Nevertheless, there is no consensus definition of MS in children. A review on the topic found 40 different definitions adapted from those proposed for adults (9). In 2007, the International Diabetes Federation (IDF) proposed the latest definition of MS for children over the age of 10 years, based on the presence of increased waist circumference plus two of the following elements: hypertriglyceridemia; low HDL cholesterol; hypertension; and impaired fasting glucose or T2DM (10). A systematic review on MS in children found 26 studies adopting this definition (11).

In a recently published study, our group demonstrated that leptin is positively associated with insulin resistance in prepubertal children after adjusting for sex, age, and body mass index (BMI) Z-score (12). Other authors reported similar results in children $(13,14)$, suggesting a role of leptin as a potential modulator of glucose metabolism and insulin resistance, regardless of obesity. These studies highlight the importance of leptin as a cardiovascular risk marker in this age group.

Identification of potential new risk markers for cardiovascular disease in children could contribute to the development of early intervention strategies, particularly preventive ones. However, no published studies have proposed serum leptin level cutoffs for the pediatric population.

Within this context, the objectives of this study are to ascertain, within a case series of prepubertal children with normal and excess weight, which serum leptin value best suited to identify MS, and to evaluate the association between leptin and MS.

\section{SUBJECTS AND METHODS}

This observational, cross-sectional study recruited children from the outpatient general pediatrics clinic of
Hospital Universitário Pedro Ernesto da Universidade do Estado do Rio de Janeiro (HUPE-UERJ), a teaching hospital in Rio de Janeiro, Brazil, with the purpose of validating serum leptin level cutoffs to identify MS. All children aged 5-11 years who were prepubertal, overweight or obese, otherwise healthy, and were not taking part in any weight loss program were invited to take part in the study. All eligible children who met these criteria were included. Normal-weight, healthy, prepubertal children, matched by age, from the same Pediatric well-child care clinic were recruited as controls, selected in a first-come first-serve order from May 2008 to December 2011. Study sample size, 275 children, was considered sufficient to achieve statistical power of $80 \%$, with a level of significance set at $5 \%$, for an error of $5 \%$, based on the total population of children seen at the clinic (15).

The children recruited for the study underwent a complete clinical assessment. Weight was measured with the participants barefoot and wearing minimal clothing, on a Filizola scale (Filizola, São Paulo, SP, Brazil) with a resolution of $100 \mathrm{~g}$. Height was measured with a Harpenden-type wall-mounted stadiometer (Tonelli, Criciúma, SC, Brazil) with a resolution of 1 $\mathrm{mm}$. Waist circumference was measured at just above the uppermost lateral border of the right ilium, at the end of a normal expiration, as recommended in the Third National Health and Nutrition Examination Survey (NHANES III) Anthropometry Procedures Manual (16), using a Mabbis ${ }^{\circledR}$ Gulick-type tape measure (Cardiomed, Curitiba, PR, Brazil).

Blood pressure was measured in the right arm using the auscultatory method, with each participant in the sitting position and at rest, using a $\mathrm{Tycos}^{\circledR}$ aneroid sphygmomanometer (Welch Allyn Company, Arden, DE, USA) with cuffs of appropriate size.

Blood was collected for laboratory testing after a 12hour fast. Glucose, total cholesterol, HDL cholesterol, and triglycerides were measured in a Konelab analyzer with the BT 3000 Winer kit, which employs the following assay methods: for glucose, the GOD-PAP (oxidase) enzymatic method; for cholesterol, the CHOP-POD (esterase/oxidase) enzymatic method; for triglycerides, the GPO-PAP (oxidase) enzymatic method; and for HDL cholesterol, the enzymatic colorimetric method (Winterlab, Rosario, Santa Fe, Argentina).

Insulin was measured in a Gamma-C12 counter using the Coat-A-Count solid-phase ${ }^{125}$ I-labeled radioimmunoassay (DPC, Los Angeles, CA, USA). The 
intra-assay and inter-assay coefficients of variation were $3.1-9.3 \%$ and $4.9-10.0 \%$ respectively.

Leptin wasalso measured in the Gamma-C12 counter, using the double antibody PEG radioimmunoassay method, with a kit that uses ${ }^{125}$ I-labeled human leptin and human leptin antiserum (Linco Research, St. Charles, MO, USA). The intra-assay and inter-assay coefficients of variation were $3.4-8.3 \%$ and $3.0-6.2 \%$ respectively.

The HOMA-IR score was calculated by multiplying the fasting blood glucose (in $\mathrm{mmol} / \mathrm{L}$ ) by the fasting insulin level (in $\mu \mathrm{IU} / \mathrm{mL}$ ) and dividing the product by 22.5, as noted elsewhere (17).

Obesity, overweight, and normal weight were defined using the BMI for sex and age standards proposed by the World Health Organization (WHO). The criteria are as follows: a body mass index (BMI) $\mathrm{Z}$-score greater than +2 denotes obesity; greater than +1 and less than or equal to +2 , overweight; and greater than or equal to -2 and less than or equal to +1 , normal weight (18).

The definition of MS was adapted from the IDF proposal for children over the age of 10 years (10), and waist circumference was defined as increased when the measurement was within or above the $90^{\text {th }}$ percentile for sex and age in the NHANES III table that combines children of African-American, European-American, and Mexican-American ethnicity (16). Hypertension was defined according to the criteria recommended in the $1^{\text {st }}$
Brazilian Guideline on the Prevention of Atherosclerosis in Childhood and Adolescence (19). The cutoff points adopted for fasting blood glucose, HDL cholesterol, and triglycerides were those recommended by the same guideline: impaired fasting glucose, values $\geq 5.6$ $\mathrm{mmol} / \mathrm{L}(100 \mathrm{mg} / \mathrm{dL})$; low HDL cholesterol, values < $1.16 \mathrm{nmol} / \mathrm{L}(45 \mathrm{mg} / \mathrm{dL})$; and increased triglycerides, values $\geq 1.46 \mathrm{mmol} / \mathrm{L}(130 \mathrm{mg} / \mathrm{dL})(19)$.

The collected data were entered into Excel 7 spreadsheets (MapInfo Corporation, Troy, NY, USA) and analyzed in R-Project 3.0.1 (Free Software Foundation, Boston, MA, USA).

Simple and multivariate logistic models, the latter adjusted for sex and age and both having serum leptin levels as the main predictor, were used to predict MS. The results obtained were used to construct two receiver operator characteristic (ROC) curves.

The present study was approved by the HUPEUERJ Research Ethics Committee with protocol no. 173-CEP/HUPE-CAAE; 0020.0.228.000-07. It is also registered with the Brazilian National Research Ethics Commission under number 127374.

\section{RESULTS}

Table 1 describes the clinical and metabolic profile of study participants stratified by nutritional status is provided. A comparison between the MS and no MS groups is shown in Table 2 .

Table 1. Profile of study participants stratified by nutritional status

\begin{tabular}{|c|c|c|c|c|}
\hline Parameter & Obese children & Overweight children & Normal weight children & P-value \\
\hline Participants, n (\%) & $164(59.6)$ & $46(16.7)$ & $65(23.6)$ & \\
\hline Age in months & $94.68 \pm 17.70$ & $92.93 \pm 18.68$ & $91.85 \pm 17.51$ & 0.52 \\
\hline \multicolumn{5}{|l|}{ Sex } \\
\hline Male & $104(63.4)$ & $21(45.7)$ & 35 (53.8) & 0.07 \\
\hline Female & $60(36.6)$ & $25(54.3)$ & $30(46.2)$ & \\
\hline Metabolic syndrome & 33 (97.1) & $1(2.9)$ & $0(0)$ & 0.00001 \\
\hline Total cholesterol in mg/dL & $166.43 \pm 30.78$ & $166.22 \pm 30.36$ & $153.52 \pm 33.75$ & 0.02 \\
\hline $\mathrm{HDL}$ cholesterol in mg/dL ${ }^{\S}$ & $41.90 \pm 9.00$ & $52.48 \pm 12.89$ & $49.15 \pm 11.70$ & 0.00001 \\
\hline LDL cholesterol in mg/dL ${ }^{\ddagger}$ & $103.90 \pm 28.67$ & $98.22 \pm 30.64$ & $89.82 \pm 30.17$ & 0.001 \\
\hline Triglycerides in mg/dL§ & $102.96 \pm 55.35$ & $77.96 \pm 30.08$ & $72.86 \pm 28.40$ & 0.00001 \\
\hline $\mathrm{HOMA}-\mathrm{IR}^{\dagger}$ & $2.15 \pm 1.83$ & $1.67 \pm 1.02$ & $0.78 \pm 0.67$ & 0.00001 \\
\hline Glucose in mg/dL & $86.64 \pm 8.72$ & $86.78 \pm 7.52$ & $84.45 \pm 7.21$ & 0.16 \\
\hline Leptin in ng/mL* & $18.6 \pm 14.47$ & $9.64 \pm 9.05$ & $3.29 \pm 2.83$ & 0.00001 \\
\hline
\end{tabular}

Data expressed as absolute and relative frequencies (\%) or mean \pm standard deviation. Tukey test: * showed significant difference between all categories (obese, overweight, and normal weight children); ${ }^{\dagger}$ showed significant difference between obese and normal weight children and between overweight and normal weight children; ${ }^{\ddagger}$ showed significant difference between obese and normal weight children; § showed significant difference between obese and normal weight children and between obese and overweight children. 
Table 2. Profile of study participants stratified by metabolic syndrome status

\begin{tabular}{lccc}
\hline Parameter & $\begin{array}{c}\text { Metabolic } \\
\text { syndrome }\end{array}$ & $\begin{array}{c}\text { No metabolic } \\
\text { syndrome }\end{array}$ & P-value \\
\hline Participants, n (\%) & $34(12.4)$ & $241(87.6)$ & \\
Age in months & $103.17 \pm 18.6$ & $92.4 \pm 17.3$ & 0.0009 \\
Sex & & & \\
$\quad$ Male & $23(67.6)$ & $137(56.8)$ & 0.23 \\
$\quad$ Female & $11(32.4)$ & $104(43.2)$ & \\
BMl z-score & $3.54 \pm 1.19$ & $1.96 \pm 1.77$ & 0.00001 \\
Total cholesterol in mg/dL & $175.6 \pm 25.1$ & $161.6 \pm 32.3$ & 0.02 \\
HDL cholesterol in mg/dL & $36.8 \pm 4.6$ & $46.6 \pm 11.4$ & 0.00001 \\
LDL cholesterol in mg/dL & $103.6 \pm 24.7$ & $99.1 \pm 30.5$ & 0.41 \\
Triglycerides in mg/dL & $176.5 \pm 62.4$ & $79.7 \pm 31.4$ & 0.00001 \\
HOMA-IR & $3.3 \pm 2.7$ & $1.5 \pm 1.2$ & 0.00001 \\
Glucose in mg/dL & $88.76 \pm 7.89$ & $85.78 \pm 8.21$ & 0.046 \\
Leptin in ng/mL & $21.2 \pm 11.3$ & $12.4 \pm 13.5$ & 0.0004 \\
\hline
\end{tabular}

Data expressed as absolute and relative frequencies (\%) or mean \pm standard deviation.

a Z-score for body mass index

Waist circumference was above the $90^{\text {th }}$ percentile for age in 135 (49.1\%) children. Hypertension was detected in $4(1.45 \%)$ children, for a prevalence of $8.82 \%$ $(\mathrm{n}=3)$ in the MS group versus $0.41 \%(\mathrm{n}=1)$ in the no MS group. Impaired fasting glucose was observed in $4(1.45 \%)$ children, all of whom were obese, for a prevalence of $2.94 \%(\mathrm{n}=3)$ in the MS group versus $1.24 \%(\mathrm{n}=1)$ in the no MS group.

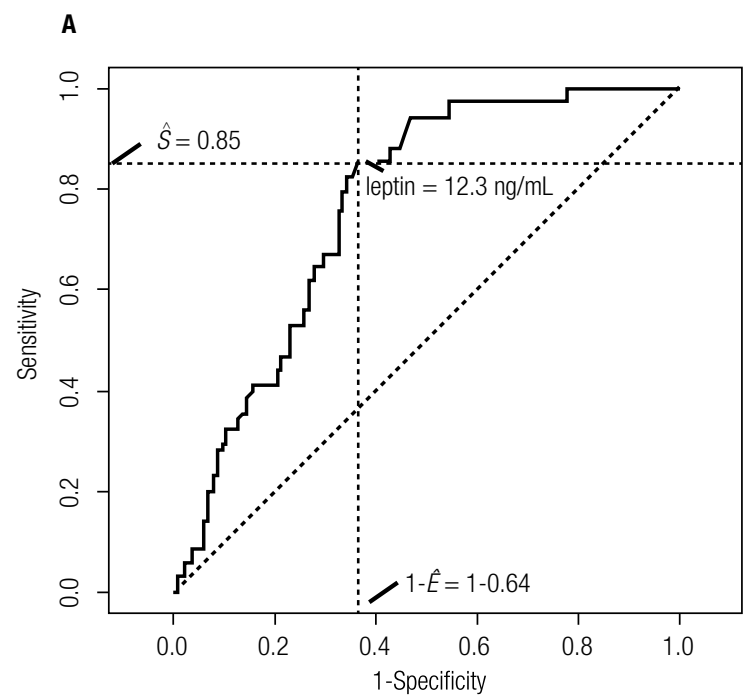

Figure 1 shows two ROC curves plotted from the sensitivity and specificity values found for each leptin level measured in the study sample, with MS as the outcome. Curve A represents the simple logistic model for prediction of MS. In this model, a leptin value of $12.3 \mathrm{ng} / \mathrm{mL}$ ( $85 \%$ sensibility; $64 \%$ specificity) corresponded to the shoulder of the curve and had the best Youden's index. Curve B represents the multiple logistic model, adjusted for sex and age. In this model, a leptin value of $13.4 \mathrm{ng} / \mathrm{mL}(68 \%$ sensibility; $69 \%$ specificity) corresponded to the shoulder of the curve and had the best Youden's index.

In the multiple logistic model for prediction of MS, adjusted for sex and age, a leptin level above $13.4 \mathrm{ng} /$ $\mathrm{dL}$ was significantly associated with MS $(\mathrm{p}=0.002)$. Figure 2 shows the odds for MS for each leptin value, according to simple and multiple logistic models.

\section{DISCUSSION}

The study sample was a very young group of children, and the substantial prevalence of metabolic syndrome according to the adapted IDF criteria is a concerning finding. We decided to use these criteria because they are currently the only standard for diagnosis of the syndrome in children and are recommended by authors who advocate that the use of unified criteria would contribute to the development of studies on the

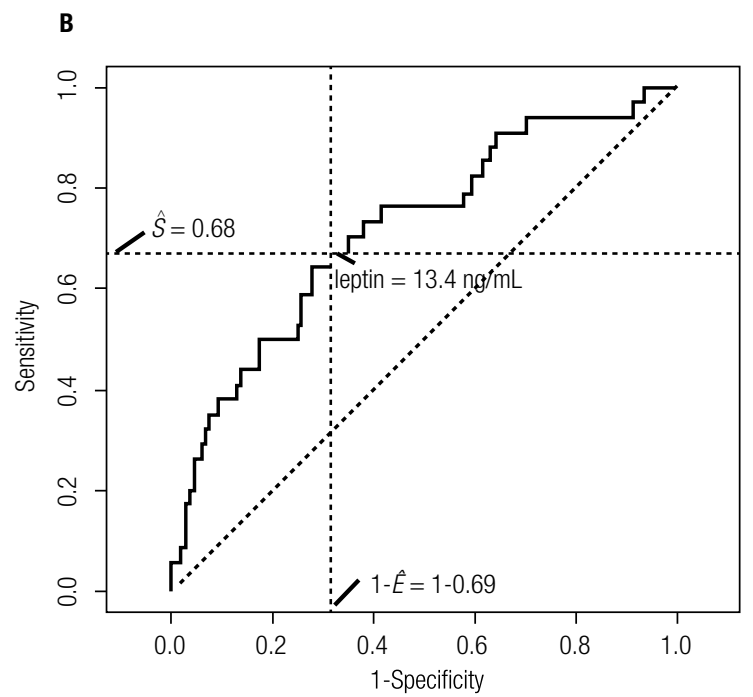

Figure 1. ROC curves of logistic regression prediction models for metabolic syndrome (response variable) in relation to the main predictor (leptin level), based on observations of prepubertal children. (A) Crude model: best cutoff point, $12.3 \mathrm{ng} / \mathrm{mL}$; area under the curve, 76.4\%; Youden's index, 48.8\%. (B) Model adjusted for sex and age: best cutoff point, $13.4 \mathrm{ng} / \mathrm{mL}$; area under the curve, $72.1 \%$; Youden's index, 36.5\%. On both charts, the best cutoff is denoted by the intersection of the dotted lines. The area under the curve represents the overall accuracy of the test. 

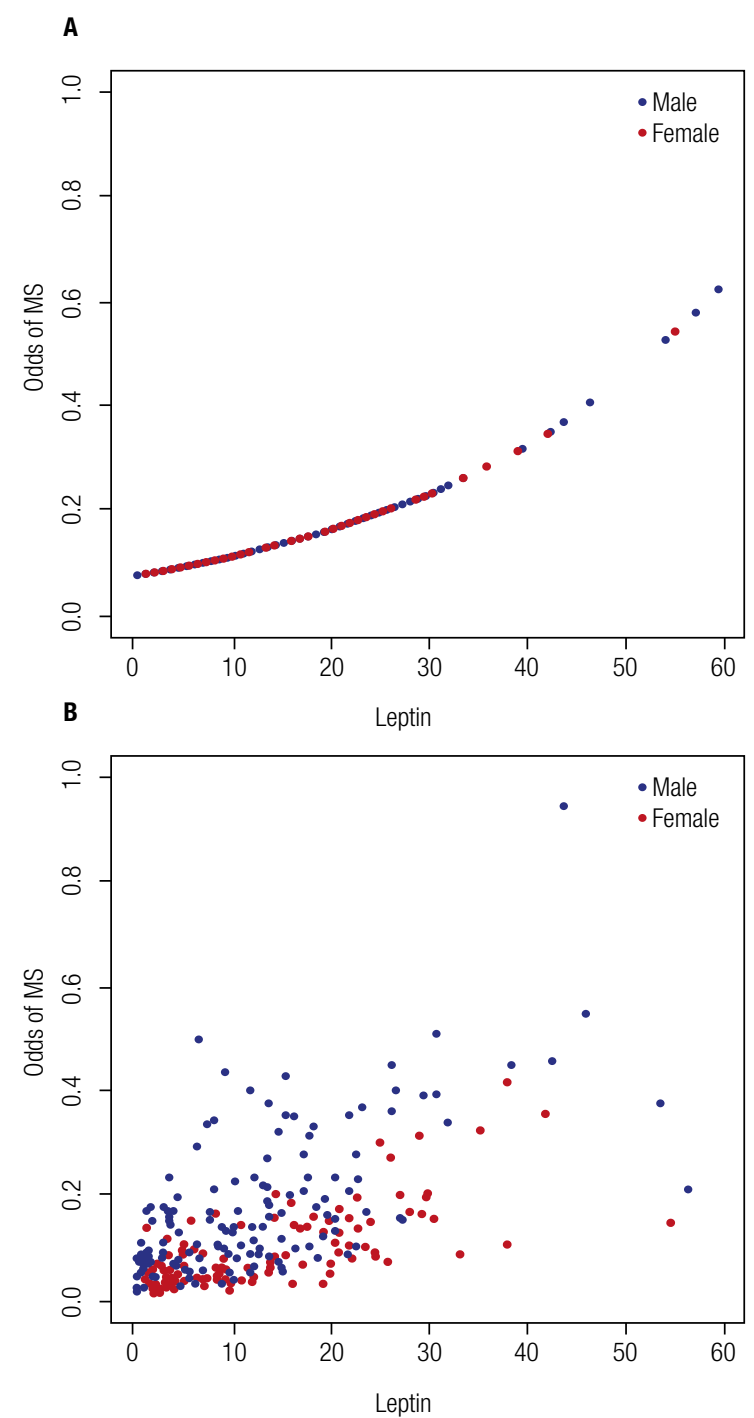

Figure 2. Odds of metabolic syndrome stratified by leptin levels ( $\mathrm{ng} / \mathrm{mL})$. (A) Crude logistic model: odds ratio $(95 \% \mathrm{Cl})=1.04(1.01-1.06) ; p<$ 0.002 ; equation for the odds of metabolic syndrome $=\exp (-2.51+0.03$ * leptin). (B) Model adjusted for sex and age: odds ratio $(95 \% \mathrm{Cl})=1.03$ $(1.01-1.06) ; p<0.002$; equation for the odds of metabolic syndrome $=$ $\exp (-5.19+0.03$ * leptin $-0,32$ * $\operatorname{sex}+0.03$ * age in months).

topic $(11,20)$. However, in view of the lack of scientific evidence for this classification in under-10 children, these criteria should only be used in clinical practice in patients who are aged 10 years or older (10).

Despite the lack of a consensus definition for MS in children and the fact that the syndrome is not a disease in itself, but rather a constellation of risk factors for cardiovascular disease, its presence in children has been reported and investigated. According to a recent systematic review, the prevalence of MS is nearly $3.3 \%$ in the whole pediatric population, $11.9 \%$ in the overweight pediatric population, and $29.2 \%$ in the obese pediatric population (11). Longitudinal studies have shown that children with MS components grow into adults with MS, and that adolescents with the syndrome are at greater risk of premature cardiovascular disease in adulthood (21). This evidence justifies the search for new biomarkers of cardiovascular risk in children with excess weight, so as to identify those at the greatest risk, understanding the concept of biomarker as an indicator of pathogenic process (22).

Leptin is one such potential biomarker (23). In children, as in adults, its circulating levels correlate strongly with body fat $(5,22)$, and high leptin levels are associated with greater fat mass growth over time (7) and with difficulty losing weight (24).

In a previous study conducted in the same population of the present study, leptin levels were positively associated with insulin resistance after adjusting for sex, age, and BMI Z-score (12).

Other authors reported similar results in studies of prepubertal children with normal and excess weight $(13,14)$, suggesting a role of leptin as a potential modulator of glucose metabolism and insulin resistance, regardless of obesity.

Knowledge of the role of leptin within this panorama has grown to a point where some authors regard it as a programming factor for future development of obesity and its correlates, possibly via epigenetic mechanisms (25).

Within this perspective, the present study ascertained that, in a sample of prepubertal children with normal and excess weight, a circulating leptin level of $13.4 \mathrm{ng} / \mathrm{mL}$ was the optimal cutoff point to identify MS. The sensitivity and specificity of this cutoff were $68 \%$ and $69 \%$ respectively, which means that its use in prepubertal children will lead to a correct diagnosis of MS in approximately two-thirds of cases and correctly rule out the syndrome in just over two-thirds of children who do not have it.

Use of this cutoff revealed an association between leptin and MS after adjusting for sex and age. The adjusted logistic model showed that, for every l-ng/dL increase in leptin levels, the odds of MS increase by $3 \%$ $(\mathrm{p}<0.002)$.

This association has been described before by other authors, including González and cols., who recruited a randomized sample of 12-to-17-year-olds (26). Papoutsakis and cols., using the IDF definition of MS in a cohort of 1,138 healthy subjects (normal-weight, overweight, and obese) with a mean age of 11.2 years, 
demonstrated that leptin is a predictor of the number of metabolic syndrome components present (27). Pedrosa and cols., using the definition of MS proposed by the National Cholesterol Education Program Adult Treatment Panel III (NCEP ATP-III), showed that presence of the syndrome was associated with high leptin levels in overweight and obese children aged 7 to 9 years $(28)$.

The novelty of the present study lies in the age range of the recruited participants. Other studies on this topic in young children are scarce, as most authors include adolescents in their series.

In view of their inherent peculiarities, prepubertal children must be studied separately from pubertal and postpubertal subjects, in whom the effects of sex steroids are already present. It has been established that insulin levels and the frequency of insulin resistance increase as puberty progresses (29). The effects of sex steroids are also reflected in leptin levels, which increase during puberty as well (26). Although studies enrolling prepubertal children exclusively are rare, it is known that some risk factors for cardiovascular disease are already present at this age, as shown in our investigation. This justifies further research into potential new biomarkers of cardiovascular risk in childhood, despite the technical difficulties inherent to study of such young subjects.

Now, more than ever, a consensus definition of MS is required (9). Development of such a definition requires proper definition of its components and of cutoffs for better identification of children at increased cardiovascular risk.

The limitations of the present study were mainly those imposed by the young age of the participants, as there is no consensus definition of the MS in this age range. In addition, some cardiovascular risk markers representative of MS, such as hypertension, impaired fasting glucose, and $\mathrm{T} 2 \mathrm{DM}$, are rare in children $(23,30)$, a finding confirmed in the present case series.

Another limitation was the areas under the curves of the ROC curves (Figure 1). Good values are 80-90, while cutoffs 70-80 are considered reasonable (15).

Study of the behavior of potential new biomarkers of cardiovascular risk in childhood may facilitate strategies for prevention and early intervention. Children with high leptin levels constitute a population to which resources and research efforts could be directed. However, due to the dearth of studies in this age group, we must stress that leptin measurement is still not applicable to pediatric clinical practice. Therefore, caution is warranted when attempting to identify young children at a supposedly increased risk of cardiovascular disease. In this age group, the most suitable approach would be to continue focusing on prophylaxis, i.e., promoting a healthy lifestyle.

Disclosure: no potential conflict of interest relevant to this article was reported.

\section{REFERENCES}

1. Flores LS, Gaya AR, Petersen RDS, Gaya A. Trends of underweight, overweight, and obesity in Brazilian children and adolescents. J Pediatr (Rio J). 2013;89:456-61.

2. Stein AD. Overweight in children: a growing problem. J Pediatr (Rio J). 2014:90:218-20.

3. Steinberger J, Daniels SR. Obesity, insulin resistance, diabetes and cardiovascular risk in children. Circulation. 2003;107:1448-53.

4. Gimeno RE, Klaman LD. Adipose tissue as an active endocrine organ: recent advances. Curr Opin Pharmacol. 2005;5:122-8.

5. Malincikova J, Stejskal D, Hrebicek J. Serun leptin and leptin receptors in healthy pubertal children: relations to insulin resistance and lipid parameters, body mass index, tumor necrosis factor alpha, heart fatty acid binding protein, and IgG anticardiolipin. Acta Univ Palacki Olomuc Fac Med. 2000;143:51-7.

6. Kalra SP. Circumventing leptin resistance for weight control. Proc Natl Acad Sci U S A. 2001;98:4279-81.

7. Fleisch AF, Agarwal N, Roberts MD, Han JC, Theim KR, Vexler A, et al. Influence of serum leptin on weight and body fat growth in children at high risk for adult obesity. J Clin Endocrinol Metab. 2007;92:948-54.

8. Konstantinides K, Schafer K, Neels JG, Dellas C, Loskutoff DJ. Inhibition of endogenous leptin protects mice from arterial and venous thrombosis. Artherioscler Thromb Vasc Biol. 2004;24:2196-201.

9. Ford ES, Li C. Defining the metabolic syndrome in children and adolescents: will the real definition please stand up? J Pediatr. 2008;152:160-4.

10. Zimmet P, Alberti G, Kaufman F, Tajima N, Silink M, Arslanian S, et al. The metabolic syndrome in children and adolescents. Lancet. 2007;369:2059-61.

11. Friend A, Craig L, Turner S. The prevalence of metabolic syndrome in children: a systematic review of the literature. Metab Syndr Relat Dis. 2013;11:71-80.

12. Madeira IR, Bordallo MAN, Carvalho CNM, Gazolla FM, Souza $\mathrm{FM}$, Matos AJ, et al. The role of metabolic syndrome components and adipokines in insulin resistance in prepubertal children. $J$ Pediatr Endocr Metab. 2011;24:289-95.

13. Valle M, Martos R, Gascón F, Cañete R, Zafra MA, Morales R. Low-grade systemic inflammation, hypoadiponectinemia and a high concentration of leptin are present in very young obese children, and correlate with metabolic syndrome. Diabetes Metab. 2005;21:55-62.

14. Slinger JD, Van Breda E, Keizer H, Rump P, Hornstra G, Kuipers $H$. Insulin resistance, physical fitness, body composition and leptin concentration in 7-8 year old children. J Sci Med Sport. 2008;11:132-8.

15. Fleiss JL, Levin BA, Levin B, Paik MC. Statistical methods for rates and proportions. 3rd ed. Oxford: Wiley InterScience; 2003.

16. Fernández JR, Redden DT, Pietrobelli A, Allison DB. Waist circumference percentiles in nationally representative samples of 
African-American, European-American, and Mexican-American children and adolescents. J Pediatr. 2004;145:439-44.

17. Matthews DR, Hosker JP, Rudenski AS, Naylor BA, Treacher DF, Turner RC. Homeostasis model assessment: insulin resistance and beta-cell function from fasting plasma glucose and insulin concentrations in man. Diabetologia. 1985;28:412-9.

18. de Onis M, Onyango AW, Borghi E, Siyam A, Nishida C, Siekmann J. Development of a WHO growth reference for school-aged children and adolescents. Bull World Health Organ. 2007;85:660-7.

19. Giuliano ICB, Caramelli B, Pellanda L, Duncan B, Mattos S, Fonseca FH. Sociedade Brasileira de Cardiologia. I Diretriz de Prevenção da Aterosclerose na Infância e na Adolescência. Arq Bras Cardiol. 2005;85(supl VI):1-36.

20. D'Adamo E, Santoro N, Caprio S. Metabolic syndrome in pediatrics: old concepts revised, new concepts discussed. Curr Probl Pediatr Adolesc Health Care. 2013;43:114-23.

21. Morrison JA, Friedman LA, Wang P, Gluec CJ. Metabolic syndrome in childhood predicts adult metabolic syndrome and type 2 diabetes mellitus 25 to 30 years later. J Pediatr. 2008;152:201-6.

22. Leoni MC, Valsecchi C, Mantelli M, Marastoni L, Tinelli C, Marchi A, et al. Impact of child obesity on adipose tissue physiology: assessment of adipocytokines and inflammatory cytokines as biomarkers of obesity. Pediatr Rep. 2010;2:e19.
23. Poyrazoglu S, Bas F, Darendeliler F. Metabolic syndrome in young people. Curr Opin Endcrinol Diabetes Obes. 2014;21:56-63.

24. Reinehr T, Kleber M, de Sousa G, Andler W. Leptin concentrations are a predictor of overweight reduction in a lifestyle intervention. Int J Pediatr Obes. 2009;4:215-23.

25. Vickers $\mathrm{MH}$, Sloboda DM. Leptin as mediator of the effects of developmental programming. Best Pract Res Clin Endocrinol Metab. 2012;26:677-87.

26. González M, del Mar Bibiloni M, Pons A, Llompart I, Tur JA. Inflammatory markers and metabolic syndrome among adolescents. Eur J Clin Nutr. 2012;66:1141-5.

27. Papoutsakis C, Yannakoulia M, Ntalla I, Dedoussis GV. Metabolic syndrome in a Mediterranean pediatric cohort: prevalence using International Diabetes Federation-derived criteria and associations with adiponectin and leptin. Metabolism. 2012;61:140-5.

28. Pedrosa C, Oliveira BM, Albuquerque I, Simões-Pereira C, Vaz-deAlmeida MD, Correia F. Obesity and metabolic syndrome in 7-9 yearsold Portuguese schoolchildren. Diabetol Metab Syndr. 2010;2:40.

29. Druet C, Dabbas B, Baltakse V, Payen C, Jouret B, Baud C, et al. Insulin resistance and the metabolic syndrome in obese French children. Clin Endocrinol (Oxf). 2006;64:672-8.

30. Sinayko AR. Metabolic Syndrome in children. J Pediatr (Rio J). 2012;88:286-8. 